\title{
Reorientação Curricular em Goiás: um processo participativo.
}

MARIA José REginato Ribeiro

MEYRI VENCI CHIEFFI*

\section{A Reorientação Curricular do 60 ao 9a ano, desenvolvida} pela Secretaria de Educação do Estado de Goiás, de 2004 a 2006, constituiu um amplo processo de discussão do currículo da segunda fase do ensino fundamental. Assumiu forma bastante participativa, atingindo todas as escolas da rede estadual, as quais atendem, no conjunto, a $70 \%$ dos alunos matriculados neste nível de escolaridade.

Seu principal objetivo foi ampliar a garantia do direito à educação de qualidade a todo adolescente e jovem desse estado, entendendo que esse direito abrange o acesso, a permanência e a conclusão, com sucesso, do ensino fundamental. Para isso, estabeleceu como metas:

- a redução das taxas de evasão e repetência nas escolas estaduais;

- a construção, pelas escolas, de propostas curriculares que considerem as aprendizagens específicas de cada área do conhecimento, o universo cultural dos alunos e as aprendizagens ligadas à leitura e à produção de texto;

- a ampliação de espaços de discussão coletiva nas escolas e nas subsecretarias.

\section{0 desafio da participação}

“(...)compreendo que a reorientação não está pronta; nós estamos construindo."

Professor da Subsecretaria Regional de Educação de Iporá

“(...)o que os professores estão gostando é que a Reorientação não está vindo de cima, estão se sentindo mais valorizados."

Professora da Subsecretaria Regional de Educação de Piracanjuba

\footnotetext{
* Maria José Reginato Ribeiro e Meyri Venci Chieffi são pedagogas e coordenadoras de projetos da área de Gestão e Sistemas de Ensino do CENPEC.
}

A opção pelo processo participativo fundamentouse no propósito de valorizar os saberes dos profissionais de ensino que atuam em diferentes níveis do sistema, especialmente dos que fazem a educação no dia-a-dia da sala de aula. A crença é de que o currículo de cada escola se modifica, de fato, à medida que o conjunto dos educadores se mobiliza para problematizar, estudar e discutir os fatores que provocam a exclusão de milhares de jovens e constroem juntos novos caminhos para a inclusão social. Quando o professor se compromete com as discussões, ele transforma sua prática, repensa o currículo.

É preciso considerar que a discussão curricular do $6^{\circ}$ ao $9^{\circ}$ ano é bastante complexa e exige um grande fôlego e vontade política das secretarias de educação na implementação de ações legais, administrativas e pedagógicas, visando a modificar a estrutura e o funcionamento do ensino nesse nível de escolaridade.

Sendo assim, para conceber o novo projeto, a secretaria foi buscar referências em um programa que havia sido iniciado em Goiás e continha iniciativas inovadoras. Trata-se do Programa Correção de Fluxo Escolar - Acelera II, que, em 2001 e 2002, envolveu escolas de 16 subsecretarias, das 38 existentes no Estado, e contou com a assessoria do Cenpec.

Este Programa, destinado aos alunos com defasagem idade-série, de $5^{\underline{a}}$ a $8^{\underline{a}}$ série, exigiu: várias mudanças na organização do ensino, como a elaboração de arranjos curriculares específicos, acompanhados da produção de materiais; a constituição de equipes multidisciplinares regionais, responsáveis pela formação continuada dos educadores dos municípios; e modificações na legislação do ensino, particularmente no que se refere à avaliação da aprendizagem dos alunos. 
As parcerias

"No Acelera tinha o Cenpec, agora temos também a Universidade, e isso é ótimo."

Professora da Subsecretaria Regional de Educação de Aparecida de Goiânia

Com base nos resultados do Acelera II e identificada com as concepções sustentadas por esse programa, a secretaria buscou novamente o Cenpec para auxiliála no novo empreendimento: ampliar a discussão curricular para toda a rede.

Considerando a necessidade de enraizar o processo de reorientação no Estado, o Cenpec propôs a ampliação dessa parceria com docentes das diferentes áreas do conhecimento de universidades locais para, com isso, favorecer a troca dos acúmulos específicos entre as diferentes instituições de ensino, a aproximação entre a formação inicial e a continuada dos professores e a continuidade da discussão curricular na rede.

A parceria entre a SUEF (Superintendência do Ensino Fundamental), o Cenpec e a Universidade foi construída processualmente, com todas as vicissitudes próprias do envolvimento de três instituições que tradicionalmente não têm a prática de trabalhar em conjunto. Isso exigiu afinação de conceitos, superação de preconceitos e desprendimento para aprender uns com os outros, o que só foi possível porque uma visão política comum unia a todos em relação à garantia do direito à educação.

Muitos foram os encontros entre os parceiros antes, durante e após os momentos de formação, além da comunicação à distância, para planejamento, avaliação e elaboração de subsídios.

Assim, em 2005 e 2006, as três instituições e os educadores do estado de Goiás desfrutaram, por várias vezes, de momentos raros em que puderam discutir suas crenças e seus fazeres pedagógicos, juntos, em um mesmo espaço. Cabe ressaltar que os locais dos encontros - a estância de Caldas Novas, a cidade histórica de Pirinópolis e a capital, Goiânia - foram cuidadosamente escolhidos para proporcionar, aos educadores, tanto as condições de trabalho necessárias, quanto possibilidades de lazer e de ampliação de seu universo cultural.

\section{A formação}

\author{
“(...) esse processo não vai ter ponto final, vai crescer \\ cada vez mais..." \\ Professora da Subsecretaria Regional de \\ Educação de Quirinópolis
}

Para que a formação chegasse a todas as escolas do Estado, ela foi organizada de forma a contemplar dois movimentos: um centralizado e outro descentralizado.

A formação centralizada reunia bimestralmente cerca de 400 educadores das 38 regiões do Estado, que tinham a responsabilidade de liderar o processo de reorientação em suas localidades. A maior parte desses educadores que compunham as equipes multidisciplinares dos órgãos regionais acumulava também a função docente em escolas da região, o que propiciava uma visão realista da pertinência das propostas e dos encaminhamentos feitos nesse fórum de discussão.

Os encontros seguiam uma determinada rotina. Iniciavam-se com a apresentação e o debate do tema, que seria norteador dos trabalhos daquele encontro, realizados por profissionais reconhecidos como autoridades no assunto.

Em um segundo momento, os educadores, agrupados por subsecretarias, traziam notícias do projeto, com a avaliação da equipe, indicando os avanços, as dificuldades encontradas e as necessidades de ajuda.

Num terceiro momento, constituíam-se os grupos por área de conhecimento, na qual o objeto de trabalho era a concepção da área e sua abordagem metodológica, o que permitia trazer as práticas de sala de aula para a análise, tendo como pano de fundo o tema norteador do encontro e as metas da reorientação.

Por fim, as subsecretarias voltavam a se reunir para planejar os momentos de formação em suas localidades.

A formação centralizada desdobrava-se, assim, regionalmente, atingindo todas as escolas, por meio de encontros das equipes multidisciplinares com os professores, coordenadores pedagógicos e diretores do ensino fundamental.

Esses encontros assumiam feições locais, mas guardavam unidade com a formação centralizada nos objetivos, na temática e nas "tarefas" comuns.

As "tarefas" a serem desenvolvidas, especialmente em uma escola específica da região, denominada escola-pes- 
quisa, consistiam numa estratégia para provocar a reflexão sobre a prática escolar, trazer a realidade da rede para a formação e instituir uma rotina de acompanhamento das equipes das subsecretarias às escolas.

Versavam sobre as questões de fundo da reorientação curricular e envolviam os profissionais das escolas num processo de ação-reflexão-ação, valorizando os desdobramentos da formação "no chão da escola".

\section{Os cadernos}

\begin{abstract}
"Ao produzir os cadernos, nos redescobrimos como produtores de conhecimento e percebemos a escrita como um importante canal de registro e documentação de um momento de grande fertilidade de diálogos na rede.”
\end{abstract}

Especialista da comissão de redação da equipe de SUEF

Os cadernos Currículo em Debate são produtos detes três anos de discussão sobre a escola, o currículo e a qualidade do processo de ensino-aprendizagem, no contexto do direito à educação.

Foram elaborados quatro cadernos, com dois grandes objetivos. O primeiro era de registrar a vida dos preciosos encontros de formação centralizada e descentralizada, sistematizando e veiculando: as discussões, as polêmicas, as práticas dos educadores, a fundamentação teórica relativa à democratização da escola e ao ensino das áreas do conhecimento, bem como "as tarefas" realizadas pelos educadores, as quais se tornavam objeto de reflexão e de estudo nos trabalhos de formação.

O outro objetivo era construir um conjunto de subsídios para alimentar a continuidade do debate coletivo dos professores e técnicos nas escolas, nos grupos de estudo dos 246 municípios do estado e nas equipes regionais e centrail da secretaria.

Os cadernos registraram as grandes temáticas norteadoras da reorientação curricular, concomitantemente aos encontros de formação. Assim, cada um teve um foco específico, a saber:

- CADERNO 1: O direito à educação - desafio da qualidade.

- CADERNO 2: Um diálogo com a rede - análise de dados e relatos.

- CADERNO 3: Currículo e práticas culturais - as áreas do conhecimento.

- CADERNO 4: Relatos de práticas pedagógicas.
A produção dos cadernos contou com a participação de todos os segmentos envolvidos no processo de reorientação, com maior ou menor intensidade, dependendo da natureza do tema.

Assim, as concepções das áreas do conhecimento e respectivas abordagens metodológicas foram propostas, discutidas e revistas várias vezes pelos professores das próprias disciplinas, de todo o Estado, nos encontros de formação, junto aos formadores do Cenpec, da SUEF e da Universidade. Esta, representada por docentes da Universidade Federal de Goiás - UFG, Universidade Estadual de Goiás - UEG e Universidade Católica de Goiás - PUC, parceiros durante todo o processo da reorientação, contribuiu com vários artigos teóricos que foram compartilhados e discutidos com os professores, com a intenção de provocar reflexões e torná-los co-autores dos documentos que expressam a reorientação curricular.

Além disso, contribuíram também com o tratamento de informações, dados e relatos trazidos pelos professores de todas as regiões do Estado. Uma comissão de redação foi constituída na SUEF, com a representação de diferentes áreas do conhecimento e a assessoria do Cenpec, para cuidar da concepção da coleção e de cada caderno, além de sua formatação.

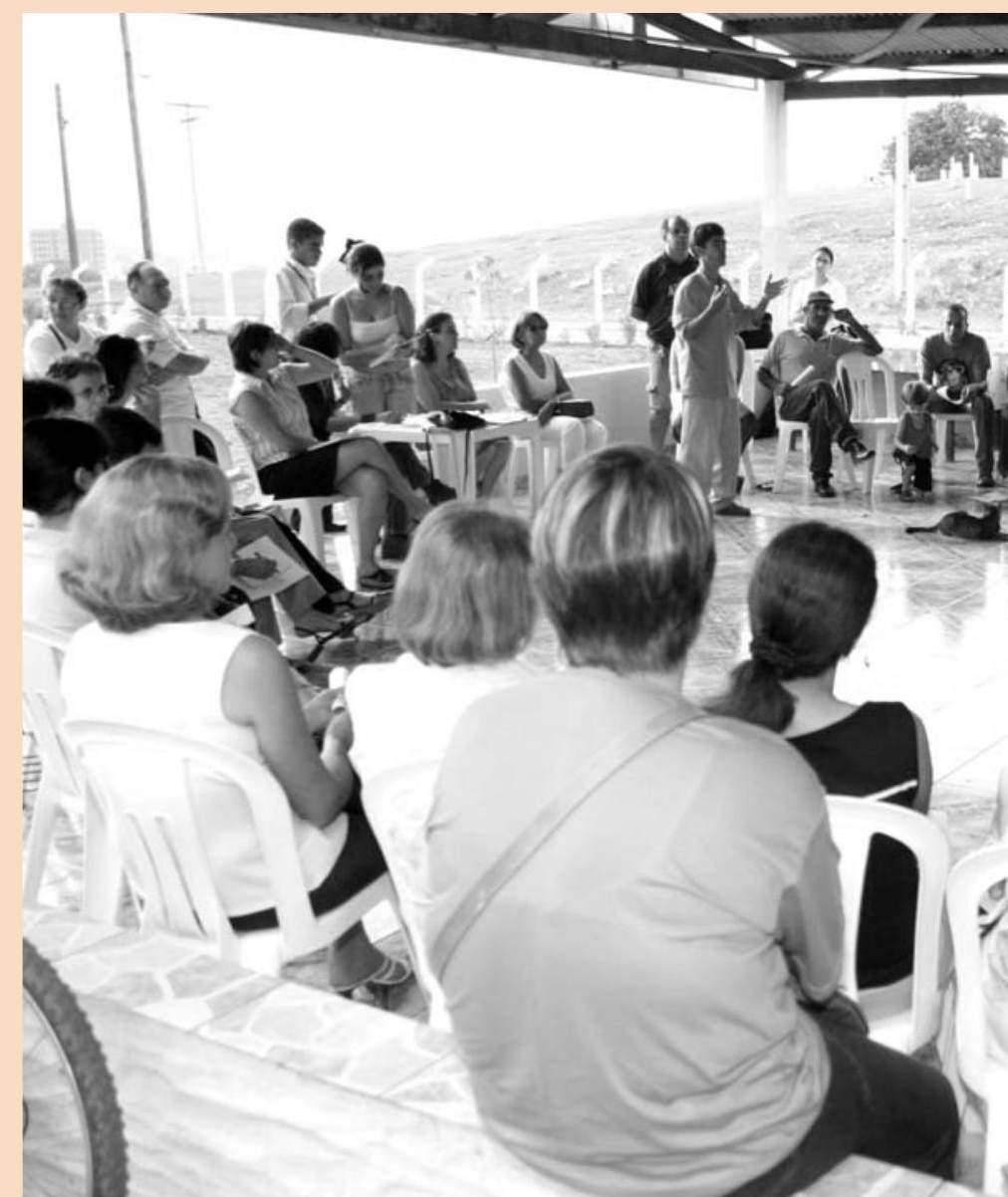


O Cenpec desempenhou também o papel de leitor crítico de toda a coleção.

Nos cadernos de Currículo em Debate, o leitor encontra as marcas do percurso feito pelos educadores de Goiás na luta pela garantia do direito à educação para toda criança e todo adolescente e, quem sabe, mesmo sendo de outro estado, apesar das distâncias e das diferenças, identifique-se com elas e se fortaleça no seu próprio percurso.

\section{Avanços e Desafios}

“(...)com a reorientação curricular estamos todos levantando e analisando os dados da escola e, com isso, alguma coisa vai mudar."

\section{Professora da Subsecretaria Regional de} Educação de Mineiros

O que garantiu que o processo de reorientação curricular fosse participativo, mobilizando maior número de agentes de educação do Estado, foram os movimentos de formação centralizada e descentralizada. Essa estratégia exigiu recursos financeiros consideráveis e deslocamento dos educadores dos mais distantes pontos de Goiás, mas foi ela que permitiu maior

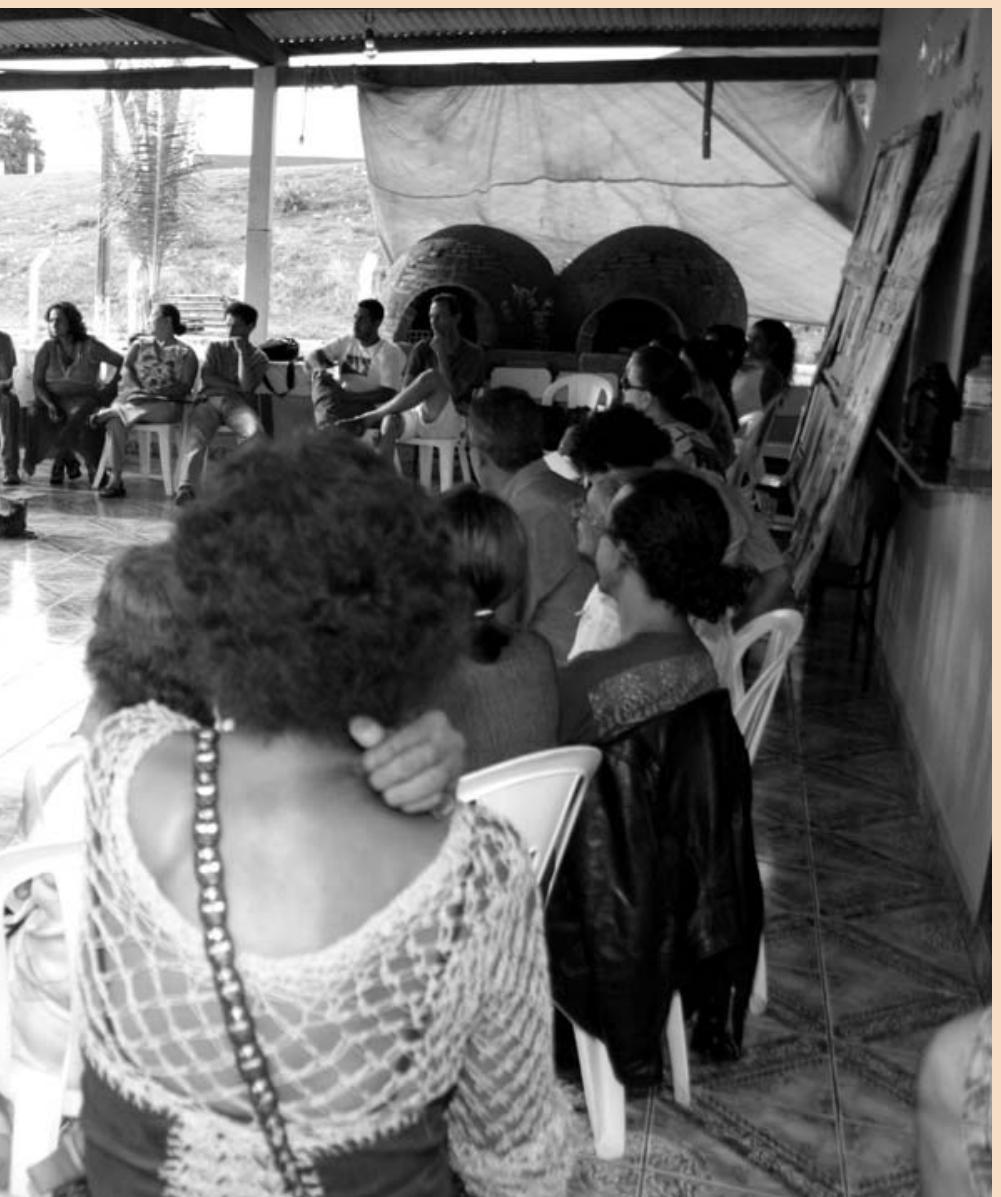

capilaridade do projeto, abrangendo praticamente todas as escolas.

O processo de acompanhamento do projeto na rede, pelas duplas pedagógicas, tanto da SUEF quanto das subsecretarias, permitiu diagnósticos e intervenções processuais nas práticas dos educadores, o que foi fundamental para a definição dos rumos da reorientação, subsidiando, desta forma, os conteúdos dos grandes encontros de formação.

As parcerias envolvidas no assessoramento à direção político-pedagógica do projeto também contribuíram muito com o processo, porque trouxeram, para o debate, múltiplos olhares e saberes específicos e complementares; a própria constituição da parceria foi, por si só, uma aprendizagem para todos.

Um ponto a se destacar foi a parceria, no financiamento do Projeto, constituída pelo Estado de Goiás e a Fundação Itaú Social numa proposta que teve, na definição de interesses e necessidades a serem atendidos, o protagonismo do poder público. Outro ponto muito valorizado foi a entrega da coleção Currículo em debate para todos os educadores da rede.

Perseguindo a mesma metodologia participativa, foi realizado um balanço coletivo, ao final de 2006 , envolvendo os mesmos 400 educadores da formação centralizada, que avaliou as três metas propostas pela reorientação curricular e fez indicações para a continuidade do processo: manter as conquistas obtidas, investir na apropriação sólida da reorientação pelas subsecretarias e escolas, repensar as atuais condições administrativas, funcionais e salariais da rede para que dêem sustentação às mudanças de práticas pedagógicas e avançar na construção de propostas curriculares inclusivas.

\section{Continuar o processo: este é o grande desafio de Goiás!}

Não é simples enfrentar a questão do ensino deste nível de escolaridade porque isso exige a implementação de medidas de grande complexidade, complementares entre si e que vão desde a política de educação nacional mais ampla que pressupõe um sólido programa de formação de professores, tanto inicial quanto continuada, o investimento as condições de trabalho dos educadores até a implementação de uma nova cultura, no interior das escolas, que rompa com o elitismo e o isolacionismo que desconsidera as vozes dos jovens, dos professores, dos pais.

Mas ousar é necessário. É preciso. 


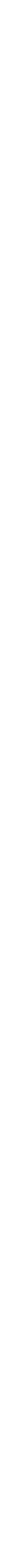

